\title{
Serpentine plant MLO proteins as entry portals for powdery mildew fungi
}

\author{
R. Panstruga ${ }^{1}$
}

Max-Planck Institute for Plant Breeding Research, Carl-von-Linné-Weg 10, 50829 Köln, Germany

\begin{abstract}
In the dicotyledonous plant species Arabidopsis and the monocot barley, presence of specific isoforms of the family of heptahelical plasma membrane-localized MLO proteins is required for successful host-cell invasion by ascomycete powdery mildew fungi. Absence of these MLO proteins, either caused by natural polymorphisms or induced lesions in the respective Mlo genes, results in failure of fungal sporelings to penetrate the plant cell wall. As a consequence, recessively inherited cell-autonomous mlo resistance is effective against all known isolates of powdery mildew fungi colonizing either barley or Arabidopsis. Barley MLO interacts constitutively with the cytoplasmic calcium sensor calmodulin, but the strength of this interaction increases transiently during fungal pathogenesis. In addition, MLO as well as ROR2, a plasma membrane-resident syntaxin also implicated in mlo penetration resistance, focally accumulate at sites of attempted fungal attack, thereby defining a novel pathogen-triggered micro-domain. In conclusion, powdery mildew fungi appear to specifically corrupt MLO to modulate vesicle-associated processes at the plant cell periphery for successful pathogenesis.
\end{abstract}

\section{Introduction}

Even though plants are constantly threatened by a plethora of potentially pathogenic microbes, surprisingly, most of the vegetation appears generally healthy. Besides preformed physical barriers, this is most probably the consequence of an elaborate surveillance system of plasma membrane-anchored and possibly also cytoplasmic immune receptors that allow plants the early recognition of potential intruders by detection of conserved molecular structures, also termed PAMPs (pathogen-associated molecular patterns) [1]. PAMP recognition triggers a multitude of biochemical responses finally resulting in the activation of defence mechanisms that suffice to effectively arrest the attempted assaults of most microbes. This innate immune response is thought to be an integral part of the genetically complex and extraordinarily durable set of defence mechanisms collectively termed 'non-host resistance' (reviewed in [2]). However, few microorganisms appear to have evolved some means to subvert the basic defence system of individual plant species, and, as a consequence, have become pathogens of these species [3]. It is conceivable that targeting and manipulation of particular host proteins is a key step of this species-specific defence sabotage [4].

\section{Mlo and the barley-powdery mildew interaction}

Powdery mildew is a common fungal disease of many monocotyledonous and dicotyledonous plant species. In a

Key words: Arabidopsis, barley, defence suppression, fungal pathogenesis, MLO, powdery mildew.

Abbreviations used: PAMP, pathogen-associated molecular pattern; SNARE, soluble Nethylmaleimide-sensitive fusion protein attachment protein receptor.

1email panstrug@mpiz-koeln.mpg.de moderately temperate and humid climate, these ascomycete fungi cause severe yield losses in a wide range of crops. For successful pathogenesis, fungal sporelings have to invade the host cell for establishment of a specialized intracellular feeding structure termed 'haustorium'. This requires penetration of the host cell wall as well as invagination of the host plasma membrane to accommodate the emerging fungal haustorium [5].

In barley, presence of the MLO protein is an absolute requirement for successful penetration of the host cell wall by the corresponding compatible powdery mildew species, Blumeria graminis f. sp. hordei. Barley genotypes lacking functional MLO, either due to natural genetic variation [6] or induced lesions in the Mlo gene [7,8], are resistant against all known isolates of the fungal pathogen. Owing to its broadspectrum nature and its unusual durability, recessively inherited barley mlo resistance has been a success story in European spring barley agriculture for the last 25 years [9].

\section{Is mlo disease resistance specific for powdery mildew?}

As mentioned above, it is plausible that each pathogen species evolved its own specific means to suppress and overcome general or specialized host defence mechanisms. For example, the cowpea rust fungus, Uromyces vignae, seems to interfere with the formation of thin cytoplasmic plasma membrane-cell wall adhesion sites (also known as Hechtian strands) for host-cell invasion on its host plant, cowpea [10]. In contrast, formation of Hechtian strands was not decreased at attempted penetration sites of compatible or incompatible powdery mildew species, suggesting that an induced reduction in Hechtian strands at penetration sites might be a specific pathogenic strategy of the cowpea rust 
fungus. Likewise, powdery mildew fungi appear to have specialized on MLO proteins as portals for host cell entry. Compared with Mlo wild-type plants, barley mlo mutants do not differ in the infection phenotype to a range of other phytopathogens, as for example barley leaf rust (Puccinia striiformis), stripe rust (Puccinia hordei), and the takeall fungus (Gaeumannomyces graminis) [11]. Interestingly, however, mlo mutants are more susceptible to the hemibiotrophic rice blast fungus, Magnaporthe grisea, and to the necrotrophic fungus Bipolaris sorokiniana $[12,13]$. In contrast, preliminary evidence for enhanced disease resistance of mlo genotypes to Rhynchosporium secalis (the causal agent of scald) was reported recently [14]. It remains to be examined in the future whether these differential infection phenotypes are a direct or indirect consequence of the lack of MLO function.

\section{Why does mlo resistance not prevail in nature?}

Wild barleys exhibit an enormous degree of genetic diversity (including significant polymorphism of resistance genes), rendering natural populations generally less sensitive to pathogen threat compared with genetically homogenous monocultures, nowadays typically employed in agriculture $[15,16]$. Thus, it appears that $m l o$ resistance is not required in wild populations to keep spread of the powdery mildew pathogen in check. In addition, absence of functional barley MLO is intimately associated with a range of developmentally controlled pleiotropic effects, including the spontaneous deposition of callose-containing cell wall appositions (papillae) in pathogenfree grown, unchallenged plants as well as a premature onset of leaf senescence [8,17-19]. This impaired leaf physiology ultimately results in some reduced grain yield of $m l o$ mutants compared with wild-type plants. Thus, the advantage of broad-spectrum powdery mildew resistance is entangled with a physiological penalty that initially hampered the use of mlo mutants in agriculture [17]. Finally, enhanced disease resistance of mlo mutants to a subset of hemibiotrophic and necrotrophic pathogen species (see above) might result in counter-selection of mlo mutant plants in natural environments. However, at least one mlo mutant arose naturally but was found at low frequencies in its habitat in the Ethiopian highlands [6]. This could either indicate that the recently emerged cultivation-associated polymorphism did not have sufficient time yet to spread more broadly or that mlo mutants may indeed have a competitive disadvantage in natural populations.

\section{From genes to biochemistry: what might the MLO protein do?}

Barley MLO is an integral plasma membrane-localized protein, possessing seven hydrophobic membrane-spanning helices [20]. The cytoplasmic C-terminus harbours an amphiphilic $\alpha$-helix that serves as a calmodulin binding do- main. Calcium-dependent calmodulin binding to this peptide domain was previously shown both in vitro and in vivo and contributes about half of the susceptibility-conferring activity of MLO [21]. Preliminary evidence suggests that MLO may form homooligomers and requires interplay of cytoplasmic domains for functionality [22]. Recently, a gene Ror2 (required for mlo resistance 2) that, when mutated, suppresser mlo-mediated resistance was found to encode a plasma membrane-resident syntaxin. Syntaxins belong to the superfamily of SNARE (soluble $\underline{N}$-ethylmaleimidesensitive fusion protein attachment protein receptor) proteins representing key mediators of membrane fusion events during vesicle trafficking in yeast and animal cells [23]. Lack of wildtype ROR2 partially compromises penetration resistance in mlo genotypes, suggesting that syntaxin activity is required for effective mlo resistance [24,25]. As shown by transient expression of fluorophore-tagged protein variants in barley epidermal cells, both MLO and ROR2 focally accumulate at sites of attempted fungal cell-wall penetration, whereas a range of control proteins did not exhibit this specific subcellular accumulation pattern. Thus, it appears that MLO, ROR2 and potentially additional proteins form a novel pathogen-triggered micro-domain at biotic stress sites [26]. In planta fluorescence resonance energy transfer analysis revealed that, at these subcellular regions, interaction between MLO and the cytoplasmic calcium sensor calmodulin transiently increases during successful fungal host cell invasion [26]. Moreover, fluorescence resonance energy transfer experiments and studies using the yeast split-ubiquitin method [26] uncovered direct physical interaction between MLO and ROR2. The intensity of this interaction is drastically lowered between a subset of single amino acid substitution mlo mutant proteins and wild-type ROR2 as well as between wild-type MLO and the barley variant encoded by the barley ror 2 mutant, characterized by a 31 amino acid in-frame deletion in the central region of the syntaxin protein $[25,26]$. In conclusion, MLO might modulate SNARE proteindependent and vesicle transport-associated processes at the plasma membrane, i.e. exocytosis or homotypic vesicle fusion events $[23,25,28]$. Cargo delivered by vesicles may include regulatory proteins and toxic metabolites (to defeat the microbial intruder at the site of attempted cell-wall penetration; Figure 1a) or plasma membrane material (to mediate net growth of the host plasma membrane for accommodation of the 'intracellular' fungal haustorium; Figure 1b). Current genetic data, however, strongly favour the first scenario, since the second model is difficult to reconcile with the fact that mlo/ror 2 double mutants exhibit partially restored susceptibility. Alternatively, for the regulation of membrane fusion events, MLO and the ROR2 syntaxin may form a novel biochemical complex of yet unknown function. Future analysis of biological processes governed by distinct MLO isoforms will help to elucidate the exact biochemical role of MLO proteins. Preliminary evidence suggests, for example, that AtMlos and AtMlo9 that are specifically expressed in pollen play a role during pollen tube germination (S. Noir and R. Panstruga, unpublished work). 
Figure 1 Model of assumed MLO corruption by the powdery mildew fungus in barley

The black rectangle represents a barley leaf epidermal cell attacked by the appressorial germ tube of a fungal sporeling and the grey line inside the box depicts the plasma membrane. (a) PAMP recognition and subsequent signal transduction leads to activation of the innate immunity response, including transcriptional up-regulation of defence-related genes and focal accumulation of respective gene products at the biotic stress site. MLO modulates an ROR2-dependent defence mechanism at the cell periphery. The fungus interferes with plasma membrane-localized MLO for defence suppression (broken lines). (b) The fungal pathogen stimulates transcriptional up-regulation and post-translational focal accumulation of MLO/ROR2 at attempted penetration sites (broken lines). Enhanced focal exocytosis of plasma membrane material might be required for the accommodation of the fungal haustorium.

a

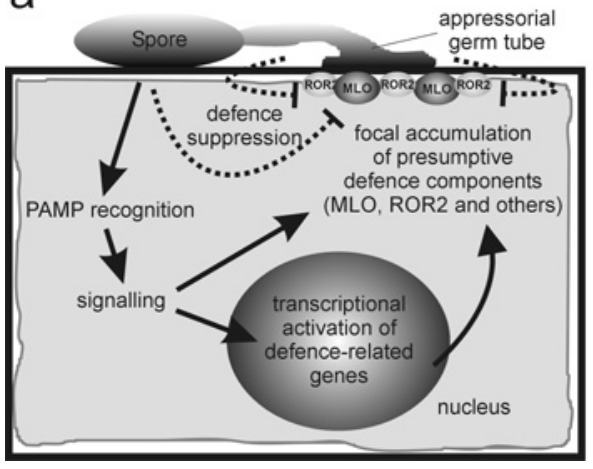

haustorium

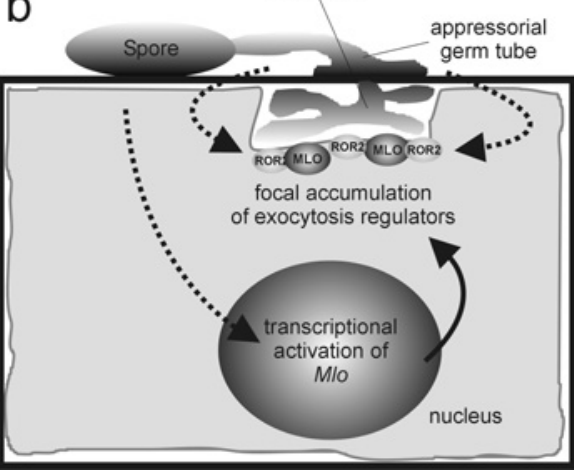

\section{Defence sabotage: how might the fungus manipulate MLO during pathogenesis?}

It is now common belief that microbial intruders in animals and plants are recognized early during attempted invasion by the presence and exposure of PAMPs to corresponding host immune receptors [1]. Thus, it is plausible to assume that powdery mildew fungi also trigger a set of biochemical activities characteristic of the innate immunity response, typically comprising altered ion fluxes, the generation of reactive oxygen species, a mitogen-activated protein kinase signalling cascade, and transcriptional activation of defence-related genes $[1,29]$. It is conceivable that the approx. 10-fold transcriptional up-regulation of $M l_{0}$ [8] and recruitment of MLO and ROR2 to biotic stress sites are integral parts of these complex defence activities. Depending on whether MLO may contribute to the delivery of toxic cargo or haustorium accommodation (see above), the fungal pathogen might either aim at dampening or stimulating MLO activity during pathogenesis (Figure 1). This could be accomplished by direct manipulation of MLO, e.g. by altering post-translational modifications like phosphorylation through fungal effector proteins. Alternatively, peptide effectors or small compounds might directly impinge on protein-protein interactions, e.g. between MLO and ROR2. The situation could be even more complex since powdery mildews might have evolved means to subvert a mechanism that originally evolved for plant defence. In tomato (Lycopersicon esculentum), for example, the tomato leaf spot fungus, Septoria lycopersici, detoxifies the steroidal phytoalexin $\alpha$-tomatine by tomatinase, an extracellular enzyme that hydrolyses glucose from the secreted antifungal compound. The cleavage product of this enzymatic reaction, $\beta_{2}$-tomatine, has significantly less antifungal capacity and, in addition, serves a role in the suppression of induced defence responses [30]. In this manner, the pathogen undermines a preformed defence barrier and specifically exploits it for defence suppression in its host plant, tomato. If a similar situation holds true for the barley-powdery mildew interaction, then the parasite might even stimulate exocytosis, in fact thought to be an integral part of a general pathogendefence pathway.

\section{Unique or not: are powdery mildew resistant mlo mutants confined to barley?}

During the last 50 years, most plant pathologists and breeders have envisaged broad-spectrum mlo resistance as an oddity of the monocot species barley. However, results recently obtained in our laboratory indicate that broad-spectrum disease resistance against powdery mildews can be induced by knocking out a particular form of the 15 Arabidopsis Mlo genes. T-DNA (transferred DNA) insertions in AtMlo2 confer enhanced resistance against all three powdery mildew species known to successfully colonize Arabidopsis thaliana (C. Consonni, R. Panstruga, M. Humphry, S. Somerville, unpublished results). This finding indicates that the capability of powdery mildew fungi to exploit MLO proteins for pathogenesis is ancient and was evolutionarily conserved for more than approx. 270 million years, the time when monocot and dicot plants were thought to have diverged from each other [31]. In other words, this means that the pathogenicity mechanism of angiosperm powdery mildew fungi had already evolved long before dinosaurs began to dominate terrestrial life [32]. In addition, this result corroborates the fact that there exists strong isoform-specificity among Mlo paralogues, since only a loss of particular MLO proteins in both Arabidopsis and barley conditions mildew resistance. It will be interesting to elucidate whether this isoform-specificity is the result 
of a particular protein feature or, alternatively, the indirect consequence of distinct gene expression patterns, as recently exemplarily demonstrated for members of the plant syntaxin protein family [33].

I thank Volker Lipka for helpful comments on the manuscript. Research in my laboratory is funded by grants of the Max-Planck Society as well as grant PA861/1 signal transduction in m/o resistance' of the Deutsche Forschungsgemeinschaft (DFG).

\section{References}

1 Nürnberger, T., Brunner, F., Kemmerling, B. and Piater, L. (2004) Immunol. Rev. 198, 249-266

2 Thordal-Christensen, H. (2003) Curr. Opin. Plant Biol. 6, 351-357

3 Heath, M.C. (1981) Phytopathology 71, 1121-1123

4 Panstruga, R. (2003) Curr. Opin. Plant Biol. 6, 320-326

5 Green, J.R., Carver, T.L.W. and Gurr, S.J. (2002) in The Powdery Mildews (Bélanger, R.R., Bushnell, W.R., Dik, A.J. and Carver, T.L.W., eds.), PP. 66-82, APS Press, St. Paul, MN, U.S.A.

6 Piffanelli, P., Ramsay, L., Waugh, R., Benabdelmouna, A., D’Hont, A. Hollricher, K., Jorgensen, J.H., Schulze-Lefert, P. and Panstruga, R. (2004) Nature (London) 430, 887-891

7 Büschges, R., Hollricher, K., Panstruga, R., Simons, G., Wolter, M., Frijters, A., van Daelen, R., van der Lee, T., Diergaarde, P. and Groenendijk, J. (1997) Cell (Cambridge, Mass.) 88, 695-705

8 Piffanelli, P., Zhou, F.S., Casais, C., Orme, J., Jarosch, B., Schaffrath, U., Collins, N.C., Panstruga, R. and Schulze-Lefert, P. (2002) Plant Physiol. 129, 1076-1085

9 Jørgensen, J.H. (1992) Euphytica 63, 141-152

10 Mellersh, D.G. and Heath, M.C. (2001) Plant Cell 13, 413-424

11 Jørgensen, J.H. (1977) Euphytica 26, 55-62

12 Jarosch, B., Kogel, K.H. and Schaffrath, U. (1999) Mol. Plant Microbe Interact. 12, 508-514

13 Kumar, J., Hückelhoven, R., Beckhove, U., Nagarajan, S. and Kogel, K.H. (2001) Phytopathology 91, 127-133

14 Makepeace, J.C., Brown, J.K.M., Oxley, S.J.P. and Burke, J.I. (2004) in 11th Rust and Mildew Conference, Norwich, U.K., poster A2.39
15 Fetch, T.G., Steffenson, B.J. and Nevok, E. (2003) Plant Dis. 87 1439-1448

16 Dreiseitl, A. and Dinoor, A. (2004) Gen. Res. Crop Evol. 51, 251-257

17 Schwarzbach, E. (1976) in Barley Genetics III (Gaul, H., ed.), pp. 440-445, Karl Thiemig Verlag, München, Germany

18 Wolter, M., Hollricher, K., Salamini, F. and Schulze-Lefert, P. (1993) Mol. Gen. Genet. 239, 122-128

19 Peterhänsel, C., Freialdenhoven, A., Kurth, J., Kolsch, R. and Schulze-Lefert, P. (1997) Plant Cell 9, 1397-1409

20 Devoto, A., Piffanelli, P., Nilsson, I., Wallin, E., Panstruga, R., von Heijne, G. and Schulze-Lefert, P. (1999) J. Biol. Chem. 274, 34993-35004

21 Kim, M.C., Panstruga, R., Elliott, C., Müller, J., Devoto, A., Yoon, H.W., Park, H.C., Cho, M.J. and Schulze-Lefert, P. (2002) Nature (London) 416 447-450

22 Elliott, C., Müller, J., Miklis, M., Bhat, R.A., Schulze-Lefert, P. and Panstruga, R. (2005) Biochem. J. 385, 243-254

23 Bock, J.B., Matern, H.T., Peden, A.A. and Scheller, R.H. (2001) Nature (London) 409, 839-841

24 Freialdenhoven, A., Peterhänsel, C., Kurth, J., Kreuzaler, F. and Schulze-Lefert, P. (1996) Plant Cell 8, 5-14

25 Collins, N.C., Thordal-Christensen, H., Lipka, V., Bau, S., Kombrink, E., Qiu, J.L., Hückelhoven, R., Stein, M., Freialdenhoven, A., Somerville, S.C. et al. (2003) Nature (London) 425, 973-977

26 Bhat, R.A., Miklis, M., Schmelzer, E., Schulze-Lefert, P. and Panstruga, R. (2005) Proc. Natl. Acad. Sci. U.S.A. 102, 3135-3140

27 Johnsson, N. and Varshavsky, A. (1994) Proc. Natl. Acad. Sci. U.S.A. 91, 10340-10344

28 Schulze-Lefert, P. (2004) Curr. Opin. Plant Biol. 7, 377-383

29 Asai, T., Tena, G., Plotnikova, J., Willmann, M.R., Chiu, W.L., Gomez-Gomez, L., Boller, T., Ausubel, F.M. and Sheen, J. (2002) Nature (London) 415, 977-983

30 Bouarab, K., Melton, R., Peart, J., Baulcombe, D. and Osbourn, A. (2002) Nature (London) 418, 889-892

31 Schneider-Poetsch, H.A.W., Kolukisaoglu, U., Clapham, D.H., Hughes, J. and Lamparter, T. (1998) Physiol. Plantarum 102, 612-622

32 Sereno, P.C., Forster, C.A., Rogers, R.R. and Monetta, A.M. (1993) Nature (London) 361, 64-66

33 Müller, I., Wagner, W., Volker, A., Schellmann, S., Nacry, P., Küttner, F., Schwarz-Sommer, Z., Mayer, U. and Jürgens, G. (2003) Nat. Cell Biol. 5 $531-534$

Received 8 October 2004 